\title{
To notify or not to notify: decision aid for policy makers on whether to make an infectious disease mandatorily notifiable
}

\author{
P Bijkerk ${ }^{12}$, EB Fanoy ${ }^{1234}$, K Kardamanidis ${ }^{1}$, SM van der Plas ${ }^{1}$, MJ te Wierik ${ }^{13}$, ME Kretzschmar ${ }^{15}$, GB Haringhuizen ${ }^{1}$, HJ van \\ Vliet ${ }^{1}$, MA van der Sande ${ }^{15}$ \\ 1. National Institute for Public Health and the Environment, Bilthoven, the Netherlands \\ 2. These authors contributed equally to the manuscript \\ 3. Public Health Service, GGD region Utrecht, Zeist, the Netherlands \\ 4. European Programme for Intervention Epidemiology Training, European Centre for Disease Prevention and Control (ECDC), \\ Stockholm, Sweden \\ 5. Julius Center, Utrecht University, Utrecht, the Netherlands
}

Correspondence: Paul Bijkerk (paul.bijkerk@rivm.nl)

Mandatory notification can be a useful tool to support infectious disease prevention and control. Guidelines are needed to help policymakers decide whether mandatory notification of an infectious disease is appropriate. We developed a decision aid, based on a range of criteria previously used in the Netherlands or in other regions to help decide whether to make a disease notifiable. Criteria were categorised as being effective, feasible and necessary with regard to the relevance of mandatory notification. Expert panels piloted the decision aid. Here we illustrate its use for three diseases (Vibrio vulnificus infection, chronic $Q$ fever and dengue fever) for which mandatory notification was requested. For dengue fever, the expert panel advised mandatory notification; for $V$. vulnificus infection and chronic Q fever, the expert panel concluded that mandatory notification was not (yet) justified. Use of the decision aid led to a structured, transparent decision making process and a thorough assessment of the advantages and disadvantages of mandatory notification of these diseases. It also helped identify knowledge gaps that required further research before a decision could be made. We therefore recommend use of this aid for public health policy making.

\section{Introduction}

Surveillance is critical to effective infectious disease control, and mandatory notification is one of its key components [1-3]. In the Netherlands and other western European countries, reporting of infectious diseases such as smallpox, tuberculosis and cholera has been mandatory by law since the end of the 19th century $[1,4,5]$. At present, countries are obliged, under the International Health Regulations (IHR) established by the World Health Organization (WHO), to notify to the WHO certain infectious diseases (e.g. a single case of poliomyelitis due to wild type polio virus) or certain outbreaks of diseases (e.g. an unexpected increase of dengue fever) that may constitute a public health emergency of international concern (PHEIC) [6]. Only the WHO has the authority to decide whether or not a very serious event constitutes a PHEIC. The European Union also requires that Member States report information on 52 infectious diseases to the European Centre for Disease Prevention and Control (ECDC) [7]. The basis of the current list of statutorily notifiable infectious diseases in the Netherlands was established at the end of 2006 by the Ministry of Health $(\mathrm{MoH})$, based on advice from the National Institute for Public Health and the Environment (RIVM) [8]. After 2006, only a few changes were made which were mainly due to international outbreaks (e.g. Middle East respiratory syndrome and pandemic influenza). In the Netherlands, physicians and heads of laboratories are required to report information about cases of specified infectious diseases or outbreaks of any diseases to the public health services. Since December 2008, 43 diseases and a group of conditions (a cluster of MRSA infections in the community, a cluster of food-borne infection or any other severe infectious disease in the community) have been mandatorily notifiable in the Netherlands [9]. A notification requirement also exists for directors of facilities for vulnerable people (e.g. nursing homes and care facilities, day care centres and schools) but was not considered in this article. The collected information is used at local level to implement preventive and control measures, and at regional and national level to monitor trends in disease and to support the development 


\section{FIGURE}

Decision tree for assessing whether an infectious disease or condition should be made notifiable
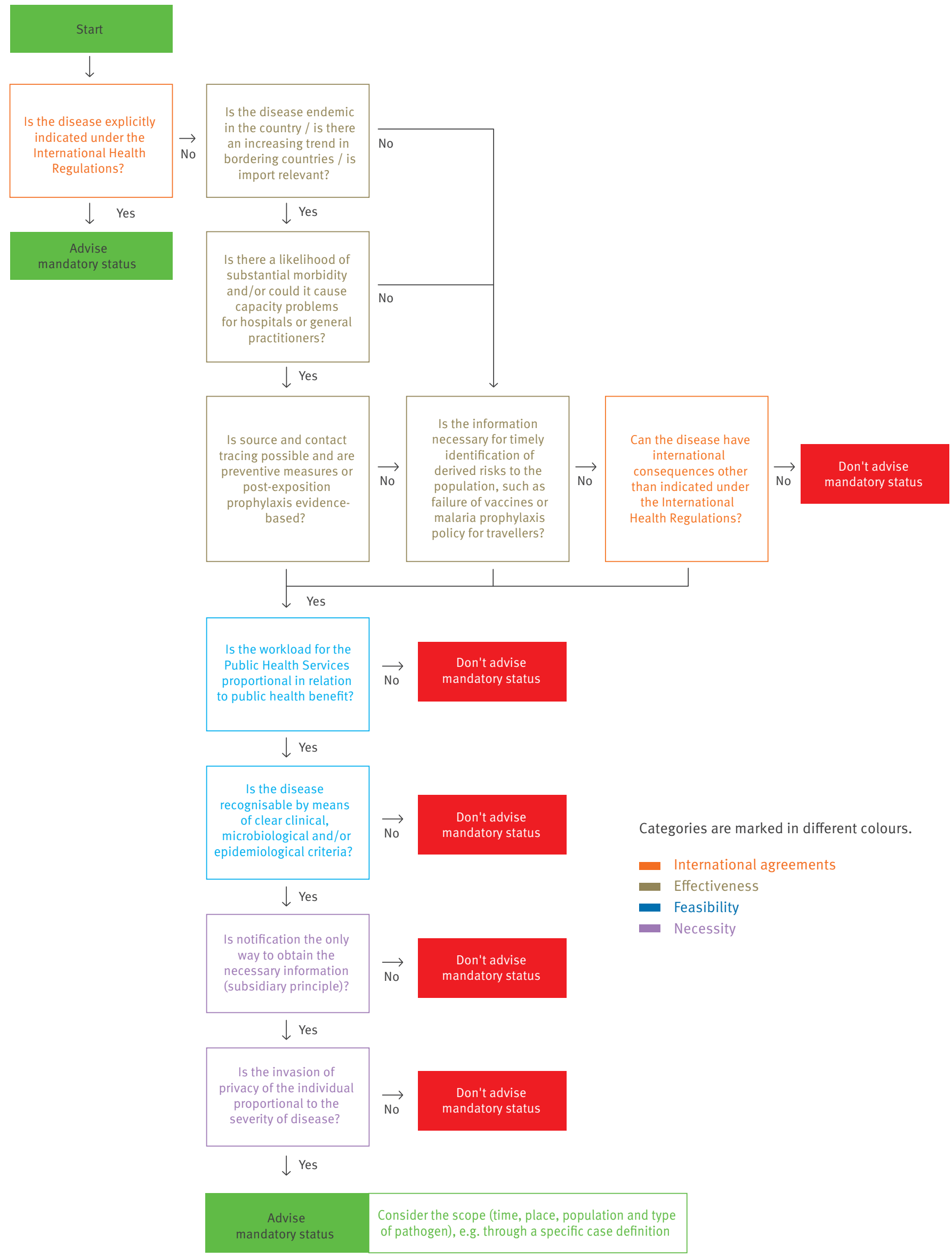
and evaluation of control guidelines and policies such as vaccination programmes or guidelines for the use of prophylaxis [10].

Statutory notification of infectious diseases can be a powerful tool to identify and control (outbreaks of) infectious diseases if notification is received in a timely manner. Advantages of notification for public health need to be balanced against disadvantages such as an increased workload for health professionals and potential intrusion into the privacy of patients [11-13]. To the best of our knowledge, there is limited published literature on tools to support the assessment of whether or not to make a disease notifiable. We therefore developed a decision aid structured as a decision tree. In this article, we describe the development of this tool, and illustrate its use while assessing recent requests to make a disease notifiable.

\section{Development of the decision aid}

We first compiled an inventory of the criteria that had to be met for the current diseases and conditions to become notifiable under the Dutch Public Health Act and under European Commission Legislation on Communicable Diseases $[6,7,9,14,15]$. In addition, we looked at criteria formulated by the WHO to decide which diseases are notifiable under the IHR (Table 1, panels A to C) [6]. We also assessed criteria used by veterinary health professionals when they had to decide which infectious pathogens in animals most likely posed a threat to human health and therefore should be monitored [16]. In addition, we considered legal constraints on public health actions in the Netherlands, i.e. criteria that must be met in an effort to protect the rights of individuals under the Dutch constitution and the European Convention on Human Rights [17] while trying to control infectious diseases in the population. Finally, we added the four Dutch additional practical criteria concerning for example the feasibility of diagnosis and the required workload for professionals in the field (Table 1, panels D to F) [10].

Similar criteria were combined. We converted these criteria into questions that can be answered with Yes or No and placed them in three categories: effectiveness (E), feasibility (F) or necessity (N). This was done because mandatory notification consists of these pillars: (E) mandatory notification leads to effective and appropriate measures; (F) notification is feasible, e.g. physicians cooperate and symptoms are recognisable; and $(\mathrm{N})$ mandatory notification is necessary, e.g. because the information can only be obtained via mandatory notification. We placed criteria from these three categories in a decision aid (Figure). The author group went through the categories in an iterative process, comparable with a Delphi process, to determine the sequence of the criteria.

Finally, we added a box at the end of the decision tree to consider the scope of notification in terms of time, place, population and pathogen. For example, mandatory notification can be in place for a limited period only or restricted to children of a certain age, a specific geographical region, or a particularly virulent subtype of a pathogen.

\section{Piloting the decision aid}

Expert panels were composed of between six and 10 experts in different disciplines with backgrounds from the laboratory or epidemiological and/or public health (policy). These expert groups piloted the decision aid by applying it to three diseases that were proposed for mandatory notification in the Netherlands: chronic Q fever, Vibrio vulnificus infection and dengue fever. Per disease, one expert panel was set up. The panel sessions were chaired by one of the authors (PB or EF) who guided the discussions box by box, taking note of the experts' opinions. Per disease, one panel session was organised. During the discussion sessions, the different criteria were rated in an iterative process until consensus was reached. When consensus was not reached, for example because the necessary scientific knowledge was lacking, we continued to answer the questions of the decision aid in both directions (Yes and No). The debatable questions were further assessed by the expert panel to enable a final conclusion.

The following chapters summarise the decision making process for each of the three diseases.

\section{Chronic Q fever (proposed in 2010)}

$\mathrm{Q}$ fever is a zoonotic disease, caused by the bacterium Coxiella burnetii. In 1 to $3 \%$ of cases of acute Q fever, the infection may become chronic. Symptoms may occur months to 10 years after primary infection, even when this was asymptomatic. Chronic Q fever may cause an inflammation of the blood vessels and heart valves, sometimes leading to endocarditis or other serious complications, and in some cases death. The Netherlands has seen a large outbreak of $Q$ fever with 3,523 human cases notified between 2007 and 2009 [18]. It is therefore expected that the number of chronic $Q$ fever cases in the Netherlands will increase in the coming years. Because chronic $Q$ fever is not notifiable, it will be difficult to identify the prevalence of chronic $Q$ fever and hence the burden of disease in the Dutch population. People with an unrecognised chronic infection may pose a risk for transmission of $C$. burnetii through blood or organ donations. A formal request was made to make chronic $Q$ fever a notifiable disease to improve surveillance. Acute $Q$ fever has been a notifiable disease in the Netherlands since 1975 because this creates the possibility to prevent new infections by tracing and treating infected sources.

Source and contact tracing for each notification of chronic $Q$ fever is hardly possible because of the long incubation period of the disease. More importantly, the assessment of the burden of disease in the population can be conducted through voluntary research and surveillance projects, for example in clinics that treat the majority of chronic $Q$ fever patients. The experts 


\section{TABLE 1}

Criteria for mandatory notification of infectious diseases to the Public Health Services, ECDC, WHO and veterinary, legal and practical considerations, classified by contribution to disease control: effectiveness, feasibility and necessity

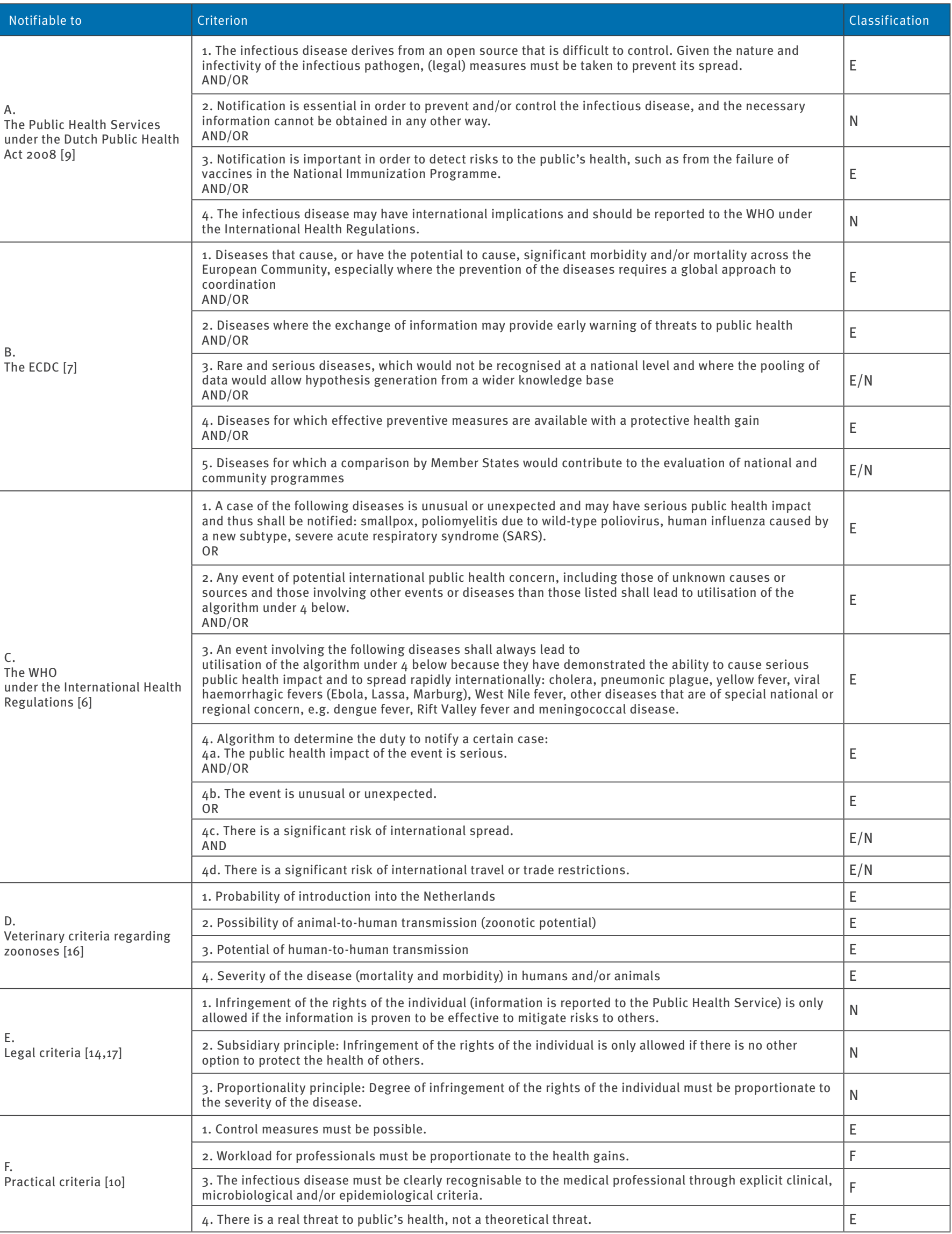

ECDC: European Centre for Disease Prevention and Control; E: effectiveness; F: feasibility; N: necessity; WHO: World Health Organization. 
were of the opinion that mandatory notification will not advance prevention and control of chronic $Q$ fever. The outcome of the decision aid for mandatory notification status was therefore a negative advice.

\section{Vibrio vulnificus infection (proposed in 2011)}

V. vulnificus is a bacterium found in raw fish and seawater. Human infections usually present as wound infections that may develop into necrotising fasciitis and sepsis, which have a mortality rate of more than $50 \%[19,20]$. Infection with $V$. vulnificus have mainly been described in the United States, where it became a notifiable disease in 2007 because of the high mortality rate and an increase in the number of infected elderly people [21]. In the Netherlands, V. vulnificus is found on an increasing number of fish (eel) farms [21]. After a worker on an eel farm died, Dutch clinicians and researchers proposed mandatory notification because of the severity of the disease and to gain insight in the epidemiology of the disease in the Netherlands [21].

Clinical infections with $V$. vulnificus occur only sporadically in the Netherlands, especially because the Dutch climate is not warm enough for growth of these bacteria [22]. It is unclear to what extent this will increase in the coming years. It is known that $V$. vulnificus infections can cause high morbidity and mortality but there is currently no risk to the wider population. Furthermore, the occurrence of $V$. vulnificus bacteria in the environment is already being monitored and was considered sufficient by the experts. Because of an increase in the number of fish farms in the Netherlands where the bacteria are found, the opportunities for control and prevention should be sought in occupational and food safety measures [21]. If a cluster of $V$. vulnificus infections in humans were to occur, this is very likely to be notified to the authorities as the notification of clusters of any severe infectious disease is mandatory. The outcome of the assessment of whether to make this disease notifiable was a negative advice.

\section{Dengue fever (proposed in 2012)}

Dengue fever is a viral infection, mainly transmitted through bites of the mosquito species Aedes aegypti. Symptoms include fever, headache, muscle and joint pains and skin rash. In a small proportion of cases, the disease develops into dengue haemorrhagic fever or dengue shock syndrome. The virus, or an efficient vector to transmit it, does not occur in the Netherlands. However, both are endemic in the Dutch Caribbean islands of Bonaire, Saba and St. Eustatius where regular outbreaks occur. In order to improve outbreak response capabilities, the Dutch Ministry of Health asked the RIVM to consider the usefulness of mandatory notification of the disease.

Dengue is no risk to the Dutch public health. The outcome of the assessment of whether to make this disease notifiable in the Netherlands was a negative advice.
According to the IHR, diseases prone to cause epidemics of special national or regional concern, such as dengue fever, must fulfil certain criteria to be notified to the WHO. A dengue outbreak can have a serious public health impact but is not unusual or unexpected as it has a seasonal occurrence on the Dutch Caribbean islands. Mandatory notification can help applying control measures. The subsequent criteria in the decision aid were met and therefore the outcome was a positive advice. Dengue fever was made a notifiable disease for the Dutch Caribbean islands only, from 1 July 2014.

Table 2 provides the exact answers to the questions posed in the decision aid.

\section{Discussion}

The decision aid supported a structured decision making process. By documenting the answers to each predetermined criterion and the rationale for the final decision, the process became more transparent. It guided the discussions and highlighted debatable criteria and therefore the need for further research to fill knowledge gaps (e.g. the effectiveness of control measures or the expected additional work required from physicians and public health services). This process is likely to increase understanding about why a disease was made notifiable and therefore acceptance among healthcare professionals.

For some diseases, the advice may be that it should be made notifiable, but only temporarily or only for a specific subpopulation (e.g. people living in healthcare facilities). This may be a compromise between the expected effectiveness of mandatory notification and its feasibility in the field. For example, during the influenza pandemic in 2009, influenza $A\left(\mathrm{H}_{1} \mathrm{~N}_{1}\right)$ pdmog was temporarily notifiable in the Netherlands. In the beginning of the pandemic, all cases were notifiable. Later in de pandemic, only severe cases who were hospitalised were notifiable. The conditions for mandatory notification were regularly reviewed to maintain a balance between the necessity of monitoring the course of the epidemic and the workload for Public Health Services.

The decision aid may not be able to accommodate all (future) situations. For example, a request to mandate the notification of drug-resistant microorganisms may require some modifications to the decision aid. Pathogens resistant to antimicrobial drugs do not always cause disease but can pose a threat to public health when they spread via carriers into hospitals or nursing homes. Moreover, the characteristics of these microorganisms, such as their potential to resist therapies or pass their resistance genes on to more virulent pathogens, may develop over time.

Furthermore, assessments can change following the introduction and establishment of a vector capable of transmitting new infections not endemic in the country or the development of new vaccines or prophylactic treatments. 
TABLE 2

Decision making process using the decision aid for mandatory notification status, by criterion and disease

\begin{tabular}{|c|c|c|c|c|}
\hline Criteria & Chronic Q fever & Vibrio vulnificus infection & $\begin{array}{l}\text { Dengue fever in the } \\
\text { Netherlands }\end{array}$ & $\begin{array}{l}\text { Dengue fever } \\
\text { in the Dutch } \\
\text { Caribbean }\end{array}$ \\
\hline $\begin{array}{l}\text { Is the disease explicitly indicated under the } \\
\text { International Health Regulations? }\end{array}$ & No & No & No & $\begin{array}{l}\text { Debatable } \\
\text { dengue is } \\
\text { indicated, but } \\
\text { only notifiable } \\
\text { when it meets } \\
\text { two of four } \\
\text { criteria. }\end{array}$ \\
\hline $\begin{array}{l}\text { Is the disease endemic in the country / } \\
\text { is there an increasing trend in bordering } \\
\text { countries / is import relevant? }\end{array}$ & Yes & Yes & $\begin{array}{l}\text { No, neither the virus } \\
\text { nor the vector are } \\
\text { endemic }\end{array}$ & Yes \\
\hline $\begin{array}{l}\text { Is there a likelihood of substantial morbidity } \\
\text { and/or could it cause capacity problems for } \\
\text { hospitals or general practitioners? }\end{array}$ & Yes & Yes & Not applicable ${ }^{b}$ & Yes \\
\hline $\begin{array}{l}\text { Is source and contact tracing possible and } \\
\text { are preventive measures or post-exposure } \\
\text { prophylaxis evidence-based? }\end{array}$ & No & $\begin{array}{l}\text { Source and contact tracing } \\
\text { is possible. But preventive } \\
\text { measures are only possible in } \\
\text { raw fish handling. It is therefore } \\
\text { debatable if notification to } \\
\text { public health services is the } \\
\text { only way to initiate measures. } \\
\text { The expert panel concluded 'No'. }\end{array}$ & Not applicable ${ }^{b}$ & Yes \\
\hline $\begin{array}{l}\text { Is the information necessary for timely } \\
\text { identification of derived risks to the } \\
\text { population, such as failure of vaccines or } \\
\text { malaria prophylaxis policy for travellers? }\end{array}$ & No & No & No & Not applicable ${ }^{b}$ \\
\hline $\begin{array}{l}\text { Can the disease have international } \\
\text { consequences other than indicated under the } \\
\text { International Health Regulations? }\end{array}$ & $\begin{array}{l}\text { No } \\
\text { Mandatory status } \\
\text { may not be } \\
\text { indicated }\end{array}$ & $\begin{array}{l}\text { No } \\
\text { Mandatory status } \\
\text { may not be } \\
\text { indicated }\end{array}$ & $\begin{array}{l}\text { No } \\
\text { Mandatory status } \\
\text { may not be } \\
\text { indicated }\end{array}$ & Not applicable ${ }^{b}$ \\
\hline $\begin{array}{l}\text { Is the workload for the public health services } \\
\text { proportional in relation to the public health } \\
\text { benefit? }\end{array}$ & Not applicable ${ }^{b}$ & Not applicable ${ }^{b}$ & Not applicable ${ }^{b}$ & Yes \\
\hline $\begin{array}{l}\text { Is the disease recognisable by clear clinical, } \\
\text { microbiological and/or epidemiological } \\
\text { criteria? }\end{array}$ & Not applicable ${ }^{b}$ & Not applicable ${ }^{b}$ & Not applicable ${ }^{b}$ & Yes \\
\hline $\begin{array}{l}\text { Is notification the only way to obtain the } \\
\text { necessary information (subsidiary principle)? }\end{array}$ & Not applicable ${ }^{b}$ & Not applicable ${ }^{b}$ & Not applicable ${ }^{b}$ & Yes \\
\hline $\begin{array}{l}\text { Is the invasion of privacy of the individual } \\
\text { proportional to the severity of disease? }\end{array}$ & Not applicable ${ }^{b}$ & Not applicable ${ }^{b}$ & Not applicable ${ }^{b}$ & Yes \\
\hline Final advice & $\begin{array}{l}\text { No, don't advise } \\
\text { mandatory status }\end{array}$ & $\begin{array}{l}\text { No, don't advise mandatory } \\
\text { status }\end{array}$ & $\begin{array}{l}\text { No, don't advise } \\
\text { mandatory status }\end{array}$ & $\begin{array}{l}\text { Yes, advise } \\
\text { mandatory } \\
\text { status }\end{array}$ \\
\hline
\end{tabular}

a If the answer to this question was debatable, we continued by answering the questions in the decision aid following both a Yes and No answer to this question.

b If the answer to a question led us to 'Don't advise mandatory status', subsequent questions were not answered and are therefore labelled with 'not applicable' in the Table. 
In our approach we designed the criteria to be scored with Yes or No: Yes for the process to proceed to the next question and No for the process to stop. Several similar studies focussing on prioritisation of communicable infectious disease have been published using a weighing approach $[11,23]$. In Germany, a study was performed to establish strategic priorities for the national public health institute. In this study, 127 infectious pathogens were prioritised in accordance with their importance for surveillance. The authors used the Delphi process with different experts to score pathogens according to a set of different criteria. Twenty-six pathogens were ranked in the group with the highest priority [11].

A Canadian study described a tool for prioritising emerging infectious diseases associated with climate change in Canada. The authors designed two different pathogen prioritisation tools. The opinion of 64 experts was elicited to assess the importance of 40 criteria that could be used to prioritise emerging infectious diseases, and a weight was calculated for each criterion. The authors stated that the tools were a simple and user-friendly approach to prioritise pathogens according to climate change by including explicit scoring of 40 criteria and incorporating weighting methods based on expert opinion [23].

The ECDC has published a literature review on risk ranking of emerging infectious disease threats [24]. This review identified a range of methods to prioritise these threats and provided an evaluation of the strengths and limitations of the available methods. Whether or not such a weighting approach would yield a more robust advice is not clear. Although our pilot experience with the current approach was positive, a weighted approach of the decision aid criteria could be studied in a future project.

\section{Conclusions and recommendations}

This decision aid guided the discussion and highlighted areas where more research is required. In the Netherlands, this aid was helpful in strengthening and harmonising the process of advising on infectious diseases notifications. We believe the decision aid could be useful for policy advisors in other countries where decisions need to be made on whether or not notification of an infectious disease should be made mandatory.

\section{Acknowledgements}

We thank Karin Haverkamp of RIVM Studio for her excellent help with the Figure. We also thank Kostas Danis for excellent advice and helpful comments on the manuscript.

\section{Conflict of interest}

None declared.
Authors' contributions

PB, EF, KK wrote the draft manuscript; PB, EF, SvdP, MtW piloted the decision aid; $\mathrm{MK}, \mathrm{GH}, \mathrm{HvV}$ and MvdS commented on earlier versions of the manuscript. All authors corrected and approved the final version.

\section{References}

1. ThackerSB, BerkelmanRL. Public health surveillance in the United States.Epidemiol Rev. 1988;10:164-90.PMID: 3066626

2. Weinberg). Surveillance and control of infectious diseases at local, national and international levels.Clin Microbiol Infect. 2005;11(Suppl 1):12-4.

3. M'ikanatha NM, Lynfield R, Van Beneden CA, de Valk H. Infectious Disease Surveillance. Oxford: Blackwell Publishing; 2007.

4. HartgerinkMJ. Health surveillance and planning for health care in the Netherlands. Int J Epidemiol. 1976;5(1):87-91. Available from: DOI: 10.1093/ije/5.1.87 PMID: 770354

5. McCormickA. The notification of infectious diseases in England and Wales.Commun Dis Rep CDR Rev. 1993;3(2):R19-25.PMID: 7693140

6. World Health Organization (WHO). International Health Regulations. Second Edition. Geneva: WHO; 2005. Available from: http://www.who.int/ihr/publications/9789241596664/ en/

7. European Commission. Decision No. 2119/98/EC of the European Parliament and of the Council of 24 September 1998 setting up a network for the epidemiological surveillance and control of communicable diseases in the Community. Official Journal of the European Union. Luxembourg: Publications Office of the European Union. 3.10.1998: L 268. Available from: http://eur-lex.europa.eu/LexUriServ/LexUriServ.do?uri=CELEX: 31998D2119:EN:HTML.

8. van Vliet JA, Timen A, Haringhuizen GB. Meldingsplicht infectieziekten in wet publieke gezondheid. [Notification of infectious diseases via the Dutch Public Health act]. Bilthoven: Rijksinstituut voor Volksgezondheid en Milieu; 2006. Dutch.

9. Bijkerk P. Melden van infectieziekten conform de Wet publieke gezondheid (2008). [Notification of infectious diseases via the Dutch Public Health act (2008)]. Bilthoven: Rijksinstituut voor Volksgezondheid en Milieu; 2008. Dutch. Available from: http://www.rivm.nl/Documenten_en_publicaties/ Wetenschappelijk/Rapporten/2008/november/Melden_van_ infectieziekten_conform_de_Wet_publieke_gezondheid_2008

10. van Vliet]A, HaringhuizenGB, TimenA, BijkerkP. [Changes in the duty of notification of infectious diseases via the Dutch Public Health Act]. Ned Tijdschr Geneeskd. 2009;153:B79. Dutch. PMID: 19818190

11. BalabanovaY, GilsdorfA, BudaS, BurgerR, EckmannsT, GärtnerB, et al. Communicable diseases prioritized for surveillance and epidemiological research: results of a standardized prioritization procedure in Germany, 2011. PLoS ONE. 2011;6(10):e25691. Available from: DOI: 10.1371/journal. pone.0025691 PMID: 21991334

12. Centers for Disease Control (CDC),CarterAO. Setting priorities: the Canadian experience in communicable disease surveillance.MMWR Morb Mortal Wkly Rep. 1992;41(Suppl):79-84.PMID: 1344268

13. DohertyJA. Establishing priorities for national communicable disease surveillance.Can J Infect Dis. 2000;11(1):21-4.PMID: 18159260

14. DuteJC, van WijngaardenJK. [Communicable diseases law: new legislation for infectious disease control]. Ned Tijdschr Geneeskd. 1999;143(20):1049-53.PMID: 10368733

15. Gezondheidsraad. De toekomst van het Rijksvaccinatieprogramma: naar een programma voor alle leeftijden. [The future of the national immunisation programme: towards a programme for all age groups]. Den Haag: Gezondheidsraad; 2007. Dutch. Available from: http:// www.gezondheidsraad.nl/sites/default/files/200702n.pdf

16. van der Giessen JWB, van de Giessen AW, Braks MAH. Emerging zoonoses: Early warning and surveillance in the Netherlands. Bilthoven: Rijksinstituut voor Volksgezondheid en Milieu; 2010. Available from: http://www.rivm.nl/Documenten en_publicaties/Wetenschappelijk/Rapporten/2010/juni/ Emerging_zoonoses_Early_warning_and_surveillance_in_the Netherlands

17. Dute JC. De wetgeving ter bestrijding van infectieziekten. [Legislation for infectious disease control]. Nijmegen: Ars Aequi Libri; 1994. Dutch. Available from: http://www.abebooks.com/ 
Wetgeving-ter-bestrijding-infectieziekten-Dute-J.C/6243599170/ bd

18. RoestHI, TilburgJJ, van der HoekW, VellemaP, van ZijderveldFG, KlaassenCH, et al. The Q fever epidemic in The Netherlands: history, onset, response and reflection. Epidemiol Infect. 2011;139(1):1-12. Available from: DOI: 10.1017/ S0950268810002268 PMID: 20920383

19. Cañigrall, MorenoY, AlonsoJL, GonzálezA, FerrúsMA. Detection of Vibrio vulnificus in seafood, seawater and wastewater samples from a Mediterranean coastal area.Microbiol Res. 2010;165(8):657-64. DOI: 10.1016/j.micres.2009.11.012 PMID: 20106642

20. OliverJD. Wound infections caused by Vibrio vulnificus and other marine bacteria.Epidemiol Infect. 2005;133(3):383-91. Available from: DOI: 10.1017/S0950268805003894 PMID: 15962544

21. DijkstraA, HaenenOL, MöllerAV. [Zoonotic bacterium: duty to notify advisable]. Ned Tijdschr Geneeskd. 2011;155:A2320. PMID: 21262025

22. DijkstraA, van IngenJ, LubbertPH, HaenenOL, MöllerAV. [Necrotizing fasciitis resulting from infection with at an eel hatchery]. Ned Tijdschr Geneeskd. 2009;153:408-11.

23. CoxR, SanchezJ, RevieCW. Multi-criteria decision analysis tools for prioritising emerging or re-emerging infectious diseases associated with climate change in Canada.PLOS ONE. 2013;8(8):e68338.

24. European Centre for Disease Prevention and Control (ECDC). Best practices in ranking emerging infectious disease threats: a literature review. Stockholm: ECDC; 2015. Available from: http://ecdc.europa.eu/en/ publications/_layouts/forms/Publication_DispForm. aspx?List $=4$ f 55 ad $51-4$ aed -4 d $32-$ b960-af70113dbb9o\&ID $=1259$

25. HavelaarAH, van RosseF, BucuraC, ToetenelMA, HaagsmaJA, KurowickaD, et al. Prioritizing emerging zoonoses in the Netherlands.PLoS ONE. 2010;5(11):e13965.http://http://dx.doi. org/10.1371/journal.pone.0013965PMID: 21085625 